\title{
Prevalence of Methicillin Resistant Staphylococcus aureus isolates from Al-Khoms hospital medical staff, Libya
}

\author{
Hassan M. Krima ${ }^{1}$, Salem M. El-Agheli ${ }^{2}$ and Bioprabhu Sanger ${ }^{3}$ \\ 1.Dept. of Medical Laboratory Technology, Higher Inst. of Medical Technology, Al-khoms, Libya. 2.Dept. of \\ Microbiology and Immunology, Faculty of Medicine, Tripoli university, Tripoli, Libya. 3. Dept. of Medical \\ Microbiology, Faculty of Medicine, Al-Margeb university, Al-khoms, Libya.
}

\begin{abstract}
The risk for acquisition of MRSA in a hospital setting by personnel; including doctors and nurses who are in contact with patients is escalating. This study was conducted to screen, isolate and identify

Staphylococcus aureus from nose and throat specimens obtained from medical and paramedical personnel in Al-Khoms Teaching Hospital, Libya.

A total of 150 persons were included in this study. Two specimens (throat and nasal swabs) were collected from each individual. Specimens were collected from medical (doctors) and paramedical staffs (nurses, technicians, midwives, and medical students), comprising both males and females with age groups ranging from 21 to 65 years, and belonging to different nationalities, departments, and clinical activities. MRSA isolates were detected by disc-diffusion and Latex agglutination method.

The study showed prevalence of MRSA positive was in nasal swabs at $14.7 \%$ and throat swabs at $9.3 \%$ of tested individuals. Libyan nurses carried the highest rate of positive MRSA cases, (75\%). Doctors, regardless of nationality, showed a lower prevalence of $25 \%$ positive MRSA. The prevalence of MRSA according to departments was found to be $43.7 \%$ in emergency, $16.2 \%$ surgery, $15.7 \%$ medicine, $33.3 \%$ in paediatrics, obstetrics and gynaecology $27.7 \%$ and renal dialysis $42.8 \%$. No recorded prevalence in ICU and physiotherapy departments, because of the small number.
\end{abstract}

Key words: MRSA, Staphylococcus aureus, Al-khoms, Libya.

\section{Introduction}

Methicillin-resistant Staphylococcus aureus (MRSA) is first and foremost a pathogen of healthcare settings. Staphylococcus aureus has been a leading cause of infection in human, since bacteria were identified as a cause of illness and death (Livermore, 2000). Staphylococcus aureus is often found in 20-30\% of the noses of normal healthy people, and is also commonly found on people's skin. (Diekema et al., 2001). With the advent of antibiotics, morbidity and mortality from S. aureus has drastically decreased, however, S. aureus has shown a remarkable ability to develop resistance to the antibiotics. This ability to develop resistance to antimicrobial agents has led, since the early 1990's, to a worldwide spread of drug resistant S. aureus (Schito, 2006).

Staphylococcus aureus strains, resistant to $\beta$-lactam antibacterial, methycillin resistant (MRSA) were emerged 40 years ago. Until the early 1990s, such strains were, by and large, confined to patients have close contact with hospitals. These strains were typically resistant to non $\beta$-lactam as well as $\beta$-lactam antibiotics. The majority of Community Acquired (CA) MRSA starts as skin infections and Hospital Acquired (HA) MRSA can begin as infections of the skin, a wound (often a surgical site) or a location where medical devices are placed (Catheters, IV lines or other devices) (Gosbell, 2004). It is the most common pathogen associated with nosocomial infections in the United States, particularly nosocomial pneumonia and surgical site infections. It is also a frequent cause of bloodstream and skin and soft tissue infections. The percentage of $S$. aureus isolates resistant to oxacillin/methicillin in U.S. intensive care units increased from $30 \%$ to $40 \%$ in the mid-1990s to $57 \%$ in 2002 (Tenover and Pearson, 2004).

The combination of S. aureus's ability to rapidly develop resistance to antibiotics, and its spread into the larger healthy community, makes MRSA infections a concern for patients, practitioners, and public and community health workers (Vriens et al., 2005). Methicillin-resistance S.aureus is widespread and most Methicillin-resistant strains are also multiple drugs resistant. (Low and Nadler., 1997).

The common site MRSA colonisation is in the nose, perineum and throat (The Swedish strategic programme against antibiotic resistance, 2010). Healthcare personnel with intermittent and persistent MRSA colonisation are an increased risk of spread of the bacteria to the patients and other healthcare personnel (Albrich and Harbarth, 2008).

The seriousness of this MRSA has reminded the author to study the Prevalence of Methicillin-resistant Staphylococcus aureus isolates from Al-Khoms hospital medical staff, Libya. The overall aim of this study is to investigate the experiences of living with MRSA colonisation and its prevalence among the healthcare professionals in the study area. 


\section{Samples and area of study}

\section{Materials and methods}

This study was conducted at the Department of Medical Microbiology, Faculty of Medicine, Al-Khoms. Two specimens (throat and nasal swabs) were collected from each of 150 individuals include male and female medical and paramedical staffs at Al-Khoms teaching hospital, Libya.

Nasal and throat swabs were collected from staff using commercially available sterilized swabs (cultiplast, Germany).

\section{Processing of specimens}

Swabs were put in tubes containing nutrient broth with 7\% Sodium chloride, in order to eliminate the commensals. Tubes were incubated at $37^{\circ} \mathrm{C}$ for 24 hours. A loopful of nutrient broth was streaked onto Mannitol Salt Agar (MSA) and Blood Agar plates for isolation of Staphylococcus sp. All isolated Staphylococcus sp. were identified using standard procedures and tested for Methicillin-resistance according to method of the National Committee for Clinical Laboratory Standards (NCCLS, 1997).

\section{Isolation of coagulase-positive Staphylococcus}

The golden yellow colonies which develop on the MSA plates were taken and tested for their coagulase activity by tube coagulase method (Murray et al., 2002). Blood agar plates were observed for $\beta$-haemolytic colonies. Mannitol nonfermenting colonies are considered coagulase-negative. Colonies with positive-coagulase reaction were further subjected to DNAase test, and were confirmed by catalase test. Disc-diffusion method and Latex Agglutination Test (Code DR0900oxoid) were also studied.

\section{Distribution of Specimens}

\section{Results and Discussions}

Hospital personnel are the potential source for the spread of MRSA within the community. Total number of 128 Libyan nationality and 22 non-Libyan were included in the present study. The percentage of males (30.7\%) and the females $(69.3 \%)$ were grouped under the occupational category with different gender (Table-1). Nurses and doctors scored high percentage with $64 \%$ and $22 \%$ respectively. The percentages of midwives and technicians were the least with $7.3 \%$ and $2 \%$ respectively. Result of various departments in the hospital (Table-2) revealed that the surgery department with the highest percentage of specimen collection (24.7\%) while the operation room had the least percentage of specimens $(0.6 \%)$. The incidence of MRSA was higher in specimens collected from paramedical staff rather than those from medical staff, indicating the significant role of paramedical staff in carriage and transmission of MRSA than the medical staff.

Table-3 illustrates the validation of throat swabs using disc-diffusion method and latex agglutination method. Out of the 46 specimens tested, 14 proved to be positive MRSA by latex agglutination method. The sensitivity of the test was determined to be $71.4 \%$ and the specificity being $100 \%$. The positive predictive value was found to be $100 \%$ while the degree of accuracy was $91.3 \%$. Here the latex agglutination method is acceptable screening for diagnosing the healthy personnel.

Table 1: Distribution of studied staff according to gender and occupation

\begin{tabular}{|c|c|c|c|c|c|c|}
\hline \multirow{2}{*}{ Occupations Gender } & \multicolumn{2}{|c|}{ Males } & \multicolumn{2}{c|}{ Females } & \multicolumn{2}{c|}{ Total } \\
\cline { 2 - 8 } & No. & $\%$ & No. & $\%$ & No. & \multicolumn{2}{c|}{$\%$} \\
\hline Doctors & 25 & 54.3 & 8 & 7.7 & 33 & 22 \\
\hline Nurses & 12 & 26.1 & 84 & 80.8 & 96 & 64 \\
\hline Technicians & 5 & 10.9 & 2 & 1.9 & 7 & 4.7 \\
\hline Midwives & 0 & 0 & 3 & 2.9 & 3 & 2.0 \\
\hline Medical students & 4 & 8.7 & 7 & 6.7 & 11 & 7.3 \\
\hline Total & 46 & 100 & 104 & 100 & 150 & 100 \\
\hline
\end{tabular}

Table 2: Distribution of studied staff according to occupation and hospital departments

\begin{tabular}{|c|c|c|c|c|c|c|}
\hline \multirow{2}{*}{$\begin{array}{ll}\text { Departments } & \text { Occupation } \\
\end{array}$} & \multicolumn{2}{|c|}{ Medical } & \multicolumn{2}{|c|}{ Paramedical } & \multicolumn{2}{|c|}{ Total } \\
\hline & No. & $\%$ & No. & $\%$ & No. & $\%$ \\
\hline Surgery & 10 & 30.3 & 27 & 23.1 & 37 & 24.7 \\
\hline Emergency & 5 & 15.1 & 11 & 9.4 & 16 & 10.7 \\
\hline Obstetrics and Gynaecology & 3 & 9.1 & 15 & 12.8 & 18 & 12.0 \\
\hline Paediatric & 5 & 15.2 & 22 & 18.8 & 27 & 18.0 \\
\hline Renal Dialysis & 3 & 9.1 & 11 & 9.4 & 14 & 9.3 \\
\hline Physiotherapy & 0 & 0 & 5 & 4.3 & 5 & 3.3 \\
\hline Total & 33 & 100 & 117 & 100 & 150 & 100 \\
\hline
\end{tabular}

Table 3: Validity of disc-diffusion method in throat swabs

\begin{tabular}{|c|c|c|c|}
\hline \multirow{2}{*}{ Disc-diffusion method } & \multicolumn{2}{|c|}{ Latex agglutination Method } & \multirow{2}{*}{ Total } \\
\cline { 2 - 4 } & positive & negative & 10 \\
\hline Positive & 10 & 0 & 36 \\
\hline Negative & 4 & 32 & 46 \\
\hline Total & 14 & 32 & \\
\hline
\end{tabular}


Table-4 depicts a total number of 42 specimens tested. Out of which 22 were found to be positive by latex agglutination method, while only 17 were positive by disc-diffusion method. As in throat specimens, here also the specificity of the method tested was found to be $100 \%$ and the sensitivity being $77.3 \%$. The test proved to be fairly feasible for the detection of healthy carriers.

Table-5 shows that MRSA was more prevalent among staff of paediatric department (25\%), emergency department (19.4\%) and surgery $(16.7 \%)$, but the lowest prevalence were among staff of medical department $(8.3 \%)$. The difference between these departments as regard to prevalence of MRSA was not statistically significant ( $>0.05)$.

Prevalence of MRSA was more prevalent in nasal swabs than throat swabs in all departments, except among staff of emergency department. The prevalence of MRSA in throat swabs was more $(71.4 \%)$ and $60 \%$ in emergency department staff and obstetrics and gynaecology department. Many reports have described the rates of nasal carriage in various populations (Uemura et al., 2004).

Table 4: Validity of disc-diffusion method in nasal swabs

\begin{tabular}{|c|c|c|c|}
\hline \multirow{2}{*}{ Disc-diffusion method } & \multicolumn{2}{|c|}{ Latex agglutination Method } & negative \\
\cline { 2 - 4 } & positive & 0 & 17 \\
\hline Positive & 17 & 20 & 25 \\
\hline Negative & 5 & 20 & 42 \\
\hline Total & 22 & & \\
\hline
\end{tabular}

Table5: Distribution of MRSA in throat and nasal swabs according to hospital departments

\begin{tabular}{|c|c|c|c|c|c|c|}
\hline \multirow{2}{*}{ Swabs } & \multicolumn{2}{|c|}{ Throat swabs } & \multicolumn{2}{|c|}{ Nose swabs } & \multicolumn{2}{|c|}{ Total } \\
\hline & No. & $\%$ & No. & $\%$ & No. & $\%$ \\
\hline Surgery & 3 & 50 & 3 & 50 & 6 & 16.7 \\
\hline Medicine & 0 & 0 & 3 & 100 & 3 & 8.3 \\
\hline Paediatric & 1 & 11.1 & 8 & 88.9 & 9 & 25 \\
\hline Emergency & 5 & 71.4 & 2 & 28.6 & 7 & 19.4 \\
\hline Obstetrics and Gynaecology & 3 & 60 & 2 & 40 & 5 & 13.9 \\
\hline Renal Dialysis & 2 & 33.3 & 4 & 66.7 & 6 & 16.7 \\
\hline I.C.U & 0 & 0 & 0 & 0 & 0 & 0 \\
\hline Physiotherapy & 0 & 0 & 0 & 0 & 0 & 0 \\
\hline Total & 14 & & 22 & & 36 & \\
\hline \multicolumn{7}{|c|}{$\chi^{2}=9.52 \quad p>0.05$} \\
\hline
\end{tabular}

MRSA was more prevalent among staff of paediatric department (25\%), emergency department (19.4\%) and surgery (16.7\%) (Table-6), but the lowest prevalence were among staff of medical department $(8.3 \%)$, the difference between these departments as regard to prevalence of MRSA was not statistically significant ( $\mathrm{p}>0.05)$.

Prevalence of MRSA was more prevalent in nasal swabs than throat swabs in all departments, except among staff of emergency department. The prevalence of MRSA in throat swabs was more, $71.4 \%$ and $60 \%$ in emergency department staff and obstetrics and gynaecology department respectively.

Table 6: Distribution of MRSA in throat and nasal swabs according to occupation and departments

\begin{tabular}{|c|c|c|c|c|c|c|c|c|}
\hline \multirow{2}{*}{ Departments } & \multicolumn{2}{|c|}{ Nurses } & \multicolumn{2}{|c|}{ Doctors } & \multicolumn{2}{|c|}{ Medical students } & \multicolumn{2}{|c|}{ Total } \\
\hline & No. & $\%$ & No. & $\%$ & No. & $\%$ & No. & $\%$ \\
\hline Surgery & 6 & 23.1 & 0 & 0 & 0 & 0 & 6 & 16.7 \\
\hline Medicine & 2 & 7.7 & 1 & 11.1 & 0 & 0 & 3 & 8.3 \\
\hline Paediatrics & 7 & 26.9 & 1 & 11.1 & 1 & 100 & 9 & 25 \\
\hline Emergency & 4 & 15.4 & 3 & 33.3 & 0 & 0 & 7 & 19.4 \\
\hline Obstetrics and Gynaecology & 2 & 7.7 & 3 & 33.3 & 0 & 0 & 5 & 13.9 \\
\hline Renal Dialysis & 5 & 19.2 & 1 & 11.1 & 0 & 0 & 6 & 16.7 \\
\hline \multirow[b]{2}{*}{ Total } & 26 & 100 & 9 & 100 & 1 & 100 & 36 & 100 \\
\hline & & 72.2 & & 25 & & 2.8 & & \\
\hline \multicolumn{9}{|c|}{$\chi^{2}=11.2 \quad \mathrm{p}>0.05$} \\
\hline
\end{tabular}

$* \chi^{2}=$ Chi-square test

Prevalence of MRSA was highest among nurses $72.2 \%$ (Table-7). Nurses of paediatric department showed the highest score $26.9 \%$, and among doctors at emergency and gynaecology and obstetrics department showed highest score $(33.3 \%)$, with no significant difference $(p>0.05)$. The high rate in nurses may be attributed to handlings of patients, perhaps nurses does not included in appropriate measures of disinfection and sterilization. 
Table7: Distribution of MRSA in throat and nasal swabs of studied staff according to their occupation and gender

\begin{tabular}{|c|c|c|c|c|c|c|}
\hline \multirow{2}{*}{ Occupation } & \multicolumn{2}{|c|}{ Males } & \multicolumn{2}{|c|}{ Females } & \multicolumn{2}{|c|}{ Total } \\
\hline & No. & $\%$ & No. & $\%$ & No. & $\%$ \\
\hline Nurses & 4 & 57.1 & 22 & 75.9 & 26 & 72.2 \\
\hline Doctors & 3 & 42.9 & 6 & 20.7 & 9 & 25 \\
\hline Medical students & 0 & 0 & 1 & 3.4 & 1 & 2.8 \\
\hline Total & 7 & 100 & 29 & 100 & 36 & 100 \\
\hline \multicolumn{7}{|c|}{$\chi^{2}=2.43 \quad \mathrm{p}>0.05$} \\
\hline
\end{tabular}

$* \chi^{2}=$ Chi-square test

Table- 8 shows that Libyan nurses scored highest prevalence of MRSA (86\%) with no significant difference. This may be due to high number of specimens from females compared to number of male nurses, but there were no reported studies about gender preference of MRSA prevalence. (Akapaka et al, 2006).

Doctors regardless of nationality, showed a lower prevalence of $4 \%$ of MRSA with no significant difference. Although MRSA prevalence was found between 16-59\% in Turkey (Aribas et al 2001).The proportion of MRSA in the various European countries recorded less than $1 \%$ in Scandinavia, to less than $30 \%$ in Spain, France and Italy.

Table 8: Distribution of MRSA in throat and nasal swabs of studied staff according to gender and nationality

\begin{tabular}{|c|c|c|c|c|c|c|}
\hline \multirow{2}{*}{$\begin{array}{l}\text { Nationality } \\
\text { Gender }\end{array}$} & \multicolumn{2}{|c|}{ Males } & \multicolumn{2}{|c|}{ Females } & \multicolumn{2}{|c|}{ Total } \\
\hline & No. & $\%$ & No. & $\%$ & No. & $\%$ \\
\hline Libyan & 7 & 100 & 25 & 86.2 & 32 & 88.2 \\
\hline Non-Libyan & 0 & 0 & 4 & 13.8 & 4 & 11.1 \\
\hline Total & 7 & 100 & 29 & 100 & 36 & 100 \\
\hline \multicolumn{7}{|c|}{$\chi^{2}=1.32 \quad p>0.05$} \\
\hline
\end{tabular}

$* \chi^{2}=$ Chi-square test

Table-9 showed prevalence rate of MRSA in selected staff by latex agglutination method which diagnostic test was $24 \%$ and $18 \%$ by disc-diffusion method with no significant difference. The efficiency of conventional method was evaluated for detection of Methicillin-resistance using disc-diffusion and the latex agglutination methods. The reason, because it is slow method and required two days to give results on disc. Other reason, conditions should be optimum for growth such as preparation of media, incubation temperature and suspension capacity of organism. The latex agglutination method as a reference test is rapid, with high sensitivity and specificity for detection of gene which encoded for resistance.

Table 9: Prevalence of MRSA in studied staff by two methods

\begin{tabular}{|c|c|c|c|c|}
\hline \multirow[b]{2}{*}{ Methods } & \multicolumn{2}{|c|}{ Disc-diffusion method } & \multicolumn{2}{|c|}{ Latex agglutination Method } \\
\hline & No. & $\%$ & No. & $\%$ \\
\hline Positive & 27 & 18 & 36 & 24 \\
\hline Negative & 123 & 82 & 114 & 76 \\
\hline Total & 150 & 100 & 150 & 100 \\
\hline \multicolumn{5}{|c|}{$\mathrm{Z}$ test $=1.28 \mathrm{p}>0.05$} \\
\hline
\end{tabular}

Table 10: Prevalence of MRSA in studied staff at different departments

\begin{tabular}{|c|c|c|c|c|c|}
\hline \multirow[b]{2}{*}{ Departments } & \multirow{2}{*}{$\begin{array}{c}\text { No. } \\
\text { Samples }\end{array}$} & \multicolumn{2}{|c|}{ Positive } & \multicolumn{2}{|c|}{ Negative } \\
\hline & & No & $\%$ & No & $\%$ \\
\hline Medicine & 19 & 3 & 15.7 & 16 & 84.3 \\
\hline Surgery & 37 & 6 & 16.2 & 31 & 83.8 \\
\hline I.C.U & 13 & 0 & 0 & 13 & 100 \\
\hline Emergency & 16 & 7 & 43.7 & 9 & 56.2 \\
\hline Obstetrics \& Gynaecology & 18 & 5 & 27.7 & 13 & 72.3 \\
\hline Pediatrics & 27 & 9 & 33.3 & 18 & 66.7 \\
\hline Operation room & 1 & 0 & 0 & 1 & 100 \\
\hline Renal Dialysis & 14 & 6 & 42.8 & 8 & 57.2 \\
\hline Physiotherapy & 5 & 0 & 0 & 5 & 100 \\
\hline Total & 150 & 36 & 24 & 114 & 76 \\
\hline \multicolumn{6}{|c|}{$\chi^{2}=15.5 \quad p>0.05$} \\
\hline
\end{tabular}


Table-10 showed high prevalence of MRSA in emergency $43.7 \%$ and renal Dialysis was $42.8 \%$, while no recorded prevalence of MRSA in I.C.U with no significant difference. This is in agreement with Fleming $e t$ al, 2006 and Moran et al., 2006, who reported that increasing numbers of MRSA in emergency departments nationwide. This was attributed to high transmission rate of $S$. aureus among medical staff, visitors and community individuals come to this department especially during admission of victims of traffic accident. High prevalence rate $(42.8 \%)$ in renal dialysis patients result is in agreement with (Okuma et al, 2002), who reported that HA-MRSA occurs most frequently among patients who undergo invasive medical procedures. No recorded positive MRSA in ICU may be due to intensive disinfection and sterilization procedures undertaken in this department. In surgery department, rate of MRSA was $16.2 \%$, but the result of Shebani et al., (2004) was (13\%).

In conclusion, considering the increasing occurrence of MRSA infections, highly reliable, accurate and rapid testing for Methicillin-resistance is essential for an infection control measures.

\section{References}

[1] Akapaka P.E,. Kissoon S., Swanston W.H and Monteil M. (2006). Prevalence and antimicrobial susceptibility pattern of Methicilin-resistant Staphylococcus aureus isolates from Trinidad and Tobago. Annals of Clinical Microbiology and Antimicrobials; 5: 1-6.

[2] Albrich W.C and Harbarth S. (2008) Health-care workers: source, vector or victim of MRSA? Lancet Infect Disease 8:289-301.

[3] Aribas E.T., Ozcan M., Altinis M. (2001). The antibiotics resistance rates of Staphylococci isolated from various clinical specimens. Infeksiyon Dergisi; 15: 369-242.

[4] Diekema D.J., Pfaller M.A., Schmitz F.J. (2001). Survey of infections due to Staphylococcus species: frequency of occurrence and antimicrobial susceptibility of isolates collected in the United States, Canada, Latin America, Europe, and the Western Pacific region for the sentry antimicrobial surveillance program. Clinical of Infectious Diseases; 32(supple2): S114-S132.

[5] Fleming W.A., Brown L.H., and Tice S.E. (2006). Community-acquired Methicillin-resistant Staphylococcus aureus skin infections: Report of a local outbreak and implications for emergency department care. Journal of the American Academy of Nurse Practitioners; 18(6): 297-300.

[6] Gosbell L.B. (2004) Methycillin Resistant - Staphylococcus aureus. Am J of Clinical Dermatology 5 (4):239-259.

[7] Livermore D.M. (2000). Antibiotic resistance in Staphylococci. International Journal of Antimicrobial Agents; 16(S), S3-S10.

[8] Low D.E and Nadler H.L. (1997). A review of in-vitro antibacterial activity of quinupristin/dalfopristin against Methicillinsusceptibility and resistant Staphylococcus aureus. Journal of antimicrobial chemotherapy; 39(supple A): 53-58.

[9] Moran G.J., Krishnadasan A., Gorwitz R.J., Fosheim G.E., McDougal L.K and Carey R.B. (2006). Methicillin-resistant Staphylococcus aureus infections among patients in the emergency department. New England Journal of Medicine; 355(7): 666674.

[10] Murray P.R., Rosenthal K.S., Kobayahi G.S and Pfaller M.A. (2002). Medical microbiology. Ed: An Affiliate of Elsevier; Fourth edition: chapter (22): 202-216.

[11] National Committee for Clinical Laboratory Standards. Performance standards for antimicrobial disk susceptibility tests. Approved standard M2-A6. Wayne, Pa: National Committee for Clinical Laboratory Standards; 1997.

[12] Okuma K., Iwakawa K and Turnidge J. (2002). "Dissemination of new Methicillin-resistant Staphylococcus aureus clones in the community". Journal of Clinical Microbiology; 40 (11): 4289-4294.

[13] Tenover F.C. and Pearson M.L. (2004) Methycillin Resistant - Staphylococcus aureus. Emerging Infectious Disease 10(11): 2052-2053.

[14] Schito G.C. (2006). The importance of the development of antibiotic resistance in Staphylococcus aureus. Clinical of Microbiology Infections; 12 (1) S: 3-8.

[15] Shebani A.O., Muftah M.I and Daw M.A. (2004). Clinical relevance of Methicillin-resistant Staphylococcus aureus isolated from surgical site infections. Jamahiriya Medical Journal; 3(2): 46-49.

[16] Uemura E., Kakinohana S., Higa N., Toma C and Nakasone N. (2004). Comparative characterization of Staphylococcus aureus isolates from throats and noses of healthy volunteers. Japanese Journal of Infectious Diseases; 57: 21-24.

[17] Vriens M.R., Blok H.E., Gigengack-Baars A.C., Mascini E.M., Chris W., Verhoef J and Troelstra A. (2005) Methicillinresistant Staphylococcus aureus Carriage among patients after hospital discharge. Infection control and hospital epidemiology; 26 (7): 629-633. 